\title{
LIFE SCIENCES
}

A nivel mundial existen cuatro factores que están provocando cambios en el sector de life sciences. Conocer estos factores es importante porque permitirá a los interesados en dicho sector implementar soluciones más adecuadas para adaptarse a los cambios.

Los factores que están provocando cambios son:

\section{Fuerzas de tecnología}

Existe una transición de la atención médica tradicional hacia la atención médica preventiva y personalizada a raíz de los avances en la tecnología y las fusiones entre el ambito computacional y biológico.

\section{Fuerzas socioeconómicas}

Los servicios de salud incrementarán su participación en el Producto Interno Bruto como consecuencia de los cambios demográficos, entre los cuáles destacan el aumento en la expectative de vida y el envejecimiento de la población.

\section{Eficiencia de capital}

Se apunta a la entrega de nuevos modelos de negocios mediante la consolidación en el área de investigación y desarrollo.

\section{Eficiencia de capital}

Los pacientes, proveedores y productores de salud son los actores más conscientes, por lo que buscan impulsar cambios en la propuesta clínica, exigen mejores resultados de valor y satisfacción del servicio. La presente investigación introduce de manera șintética el concepto de life sciences y sus principales subsectores. A continuación se presentan las principales fortalezas, oportunidades, debilidades y amenazas del sector de farmacia en la región.

Finalmente, se exploran las principales tendencias de la cadena de valor en dicho subsector.

\section{¿Qué es Life Sciences?}

El concepto de life sciences es difuso debido a la amplitud y diversidad de elementos que lo constituyen, entre los cuales se encuentran distintas ramas de la ciencia (biotecnología, bioquímica, botánica, entre otros), profesionales de otras áreas (big data, por ejemplo) hasta una serie de productos (desde quimicos de laboratorios hasta los dispositivos médicos). Siguiendo esta línea, el diccionario de Cambridge define Life Sciences como cualquier ciencia que trate con organismos vivos, sus procesos de vida y sus interrelaciones, como la biología, la medicina o la ecología.

Para EY este sector se encuentra constituido por tres subsectores:

- Dispositivos médicos: es el diseño y fabricación de equipos y suministros de tecnología médica, incluidos dispositivos médicos, diagnósticos, dispositivos de administración de fármacos e instrumentos analíticos.

- Biotecnologia: es el campo de aplicación de procesos celulares y biomoleculares para desarrollar productos y tecnologías destinados a mejorar nuestras vidas y nuestra salud.

- Farmacia: se encuentra constituido por la investigación, fabricación y comercialización de productos químicos de carácter medicinal.

Fuentes: EY.com, www.xconomy.com/, https://dictionary.cambridge.org 


\section{TENDENCIAS LIFE SCIENCES}

\section{Los subsectores del Life Sciences:}

\section{Tecnologia o dispositivos médicos}

El presente subsector abarca distintas categorías de productos, entre los cuáles destacan los siguientes:

- Diagnóstico con imágenes: Compañías que desarrollan productos para diagnosticar y monitorear condiciones mediante las tecnologias de imágenes, en las cuáles se puede incluir la radiografía, el ultrasonido, la tomografía, la ecocardiografía, la termografía, las imágenes nucleares, entre otras.

- Diagnóstico sin imágenes: Empresas que elaboran productos para diagnosticar y monitorear determinadas condiciones a través de las tecnologías sin imágenes; laboratorios, pruebas in vitro, muestras de patología, etcétera.

- Investigación y otros equipos: Compañías que desarrollan equipos para realizar investigacion y otros, entre los cuales se incluyen equipos de laboratorio especializado, análisis de datos, y más.

- Dispositivos terapéuticos: Empresas que desarrollan productos, entre los cuales destacan dispositivos terapéuticos herramientas o tecnologías para la administración e infusión de fármacos.

\section{Biotecnologia}

La noción de biotecnología se puede subdividir en varias categorias:

Biotecnologia verde:

Hace referencia al campo forestal, agrícola y ganadero. Se utiliza para crear nuevas variedades de plantas, realizar cultivos in vitro, la producción de biofertilizantes y biopesticidas, la obtención de cultivos más nutritivos y resistentes, entre otros.

Biotecnologia blanca:

Su objetivo, en los procesos industriales, es diseñar productos más eficientes, los cuales consuman menos recursos. Se destacan la creación de los biocombustibles y los alimentos procesados.
Biotecnología roja:

Se relaciona con los usos en la medicina y veterinaria. Se incluye el desarrollo de fármacos, antibióticos y vacunas, así como la terapia genética y la medicina regenerativa.

\section{Biotecnología gris:}

Se vincula con los usos aplicados al medio ambiente. En primer lugar, se busca el mantenimiento de la biodiversidad a través de técnicas de clonación y en segundo lugar, la eliminación de agentes contaminantes mediante la utilización de plantas y microrganismos.

\section{Biotecnología azul:}

Esta categoría agrupa los usos de las aplicaciones industriales con los recursos oceánicos y de aguas dulces. Entre sus usos se encuentra la utilización de los recursos para producir medicamentos, cosméticos, así como la modificación genética de especies acuaticas para aumentar su resistencia a las enfermedades.

Fuentes:

Arguedas Vargas, Ivannia, Mora Álvarez, Erick. (2014) Mapeo de la Industria de Biotecnología en Costa Rica. Tomado del sitio web PROCOMER. 


\section{TEN DENCIAS LIFE SCIENCES}

\section{Los subsectores del Life Sciences:}

A continuación se presenta un esquema sobre algunos componentes de la industria farmacéutica y el proceso para el desarrollo de fármacos.

\begin{tabular}{ll|l|l|}
\hline $\begin{array}{l}\text { Investigación y producción } \\
\text { de una molécula }\end{array}$ \\
Laboratorios de investigación. \\
- Síntesis \\
- Fermentación \\
- Extracción \\
Laboratorios farmacéuticos y \\
toxicológicos. \\
- Departamento animal \\
- Histología \\
- Histoquímica \\
- Microbiología \\
- Radioisótopos \\
- Mutagénisis \\
- Farmacodinamia \\
- Análisis Fisico y químico
\end{tabular}

\section{¿Cuál es la situación actual y las proyecciones a futuro del mercado farmacéutico y del cuidado de la salud en Centroamérica?}

Contexto general centroamericano:

Los seis países que conforman la región (Guatemala, El Salvador, Costa Rica, Honduras, Nicaragua y Panamá) combinados conforman el sexto mercado farmacéutico más grande de América Latina, el cual se ve fortalecido no solo por la expansión de la cobertura de la salud, sino que también por las ventajas comerciales que otorga el Tratado Libre de Comercio entre Estados Únidos, Centroamérica y República Dominicana. La baja penetración de medicamentos genéricos y la mejora en el acceso a los mercados a través de la estandarización de reglamentaciones regionales se vislumbran como las principales oportunidades.

A pesar de esto, el mercado centroamericano cuenta con una serie de debilidades, entre los cuales destacan un bajo gasto per cápita, lo cual limita el acceso a los servicios de salud; el poco desarrollo de las capacidades de fabricación e infraestructura, entre otros. Las principales amenazas del sector son la inestabilidad política, el poco desarrollo económico y la prevalencia de medicamentos falsificados.

Esta sección tiene como objetivo presentar cuales son las fortalezas, debilidades, oportunidades y amenazas (FODA), así como las proyecciones económicas del 2021 del sector farmacéutico y del cuidado de la salud por país.

Fuentes:

EY.com, Tait, Keith. Industria Farmaceútica. En Enciclopedia de Salud y Seguridad en el trabajo. Tomado del sitio web del INSSBT 


\section{TENDENCIAS LIFE SCIENCES}

\section{Guatemala}

\section{Fortalezas}

- Es el mercado farmacéutico más grande de la región centroamericana.

- Se beneficiará del fortalecimiento de la economía estadounidense, lo cual fortalece sus exportaciones y remesas.

\section{Oportunidades}

- El sector privado seguirá teniendo el mejor desempeño ya que la asistencia sanitaria pública sigue estando fragmentada.

- Guatemala continuará atrayendo cierto grado de inversión como el centro regional de producción farmacéutica debido a los bajos costos y al mercado relativamente grande y en crecimiento.

- Aunque las exenciones fiscales aplicables a los productores farmacéuticos se eliminaron en marzo de 2016, no se descarta volver a introducir nuevos incentivos a largo plazo.

- Comercio entre Estados Unidos, Centroamérica y República Dominicana (CAFTA-DR).

\section{Debilidades}

- Las finanzas públicas pesarán sobre el atractivo del país para la inversión en salud.

- Cualquier mejora significativa del sector sanitario público subdesarrollado y fragmentado será poco probable en el corto plazo.

\section{Amenazas}

- La corrupción dentro del sector moderará el crecimiento del mercado de salud.

- Los altos niveles de burocracia, el sistema judicial complejo y la poca seguridad obstaculizaran el crecimiento del mercado de atención médica a largo plazo.

- Incertidumbre sobre las politicas comerciales del presidente estadounidense Donald Trump hacia los países de América Latina.

Proyecciones de los productos farmacéuticos y atención médica (Guatemala 2015-2021)

\begin{tabular}{|l|l|l|l|l|l|l|l|}
\hline & 2015 & 2016 & $2017 f$ & $2018 f$ & $2019 f$ & $2020 f$ & $2021 f$ \\
\hline $\begin{array}{l}\text { Ventas farmacéuticas, } \\
\text { USDMM }\end{array}$ & 0.979 & 1,074 & 1,222 & 1,358 & 1,489 & 1,624 & 1,773 \\
\hline $\begin{array}{l}\text { Ventas farmacéuticas, } \\
\% \text { de PIB }\end{array}$ & 1.54 & 1.56 & 1.59 & 1.61 & 1.66 & 1.70 & 1.74 \\
\hline $\begin{array}{l}\text { Ventas farmaceuticas, } \\
\text { de gastos en salud }\end{array}$ & 37.8 & 38.4 & 39.9 & 41.2 & 42.7 & 44.3 & 45.9 \\
\hline $\begin{array}{l}\text { Gastos en salud, } \\
\text { USDMM }\end{array}$ & 2,589 & 2,796 & 3,064 & 3,295 & 3,489 & 3,670 & 3,860 \\
\hline
\end{tabular}

$f=$ Proyección de BMI. Fuente: Fuentes nacionales, Organización Mundial de la Salud (OMS), BMI

Fuentes:

BMlresearch.com 


\section{TENDENCIAS LIFE SCIENCES}

\section{El Salvador}

\section{Fortalezas}

- El mercado farmacéutico mantiene una trayectoria de crecimiento positiva.

- El compromiso del gobierno con la atención médica mejorará el sistema nacional de salud.

\section{Oportunidades}

- Las capacidades locales de fabricación y producción de medicamentos son limitadas, lo cual provoca dependencia de fabricantes extranjeros de medicamentos.

- Mayor aplicación de los resultados de investigación en salud en todo el sistema.

- El uso de la judicialización de la salud por parte de los pacientes crea una ventaja para los fabricantes de medicamentos innovadores de gama alta, los cuales normalmente serían denegados en el sistema público.

- La alta incidencia de cáncer crea oportunidades de generación de ingresos para fabricantes multinacionales de medicamentos y dispositivos.

\section{Debilidades}

- Los servicios de salud pública son deficientes, con largos tiempos de espera y con acceso a medicamento limitado.

- Las restricciones fiscales y una red logística deficiente producen una escasez constante de suministros farmacéuticos.

- El mercado farmacéutico es de los más reducidos en América Latina.

- Los esfuerzos de contención de costos de los regímenes de seguridad social limitarán las oportunidades de ingresos para los fabricantes de medicamentos innovadores.

- La austeridad fiscal está ejerciendo presión sobre los presupuestos destinados al sector salud del gobierno.

\section{Amenazas}

- La corrupción profundamente arraigada y las debilidades estructurales en la seguridad del país y en las instituciones judiciales socavarán el crecimiento a largo plazo de las compañias farmacéuticas.

- Existe la posibilidad de precios más estrictos y controles de reembolso.

Proyecciones de los productos farmacéuticos y atención médica (El Salvador 2015-2021)

\begin{tabular}{|l|l|l|l|l|l|l|l|}
\hline & 2015 & 2016 & $2017 \mathrm{f}$ & $2018 \mathrm{f}$ & $2019 \mathrm{f}$ & $2020 \mathrm{f}$ & $2021 \mathrm{f}$ \\
\hline $\begin{array}{l}\text { Ventas farmaceuticas, } \\
\text { USDMM }\end{array}$ & 0.527 & 0.546 & 0.558 & 0.580 & 0.603 & 0.627 & 0.655 \\
\hline $\begin{array}{l}\text { Ventas farmacéuticas, } \\
\% \text { de PIB }\end{array}$ & 2.02 & 2.04 & 2.08 & 2.07 & 2.08 & 2.07 & 2.08 \\
\hline $\begin{array}{l}\text { Ventas farmacéuticas, } \\
\% \text { de gastos en salud }\end{array}$ & 30.0 & 30.3 & 30.6 & 31.1 & 31.6 & 32.1 & 32.7 \\
\hline $\begin{array}{l}\text { Gastos en salud, } \\
\text { USDMM }\end{array}$ & 1,759 & 1,804 & 1,825 & 1,861 & 1,906 & 1,953 & 2,005 \\
\hline
\end{tabular}

$f=$ Proyección de BMI. Fuente: Organización Mundial de la Salud (OMS), Fuentes nacionales BMI

Fuentes:

BMlresearch.com 


\section{TENDENCIAS LIFE SCIENCES}

\section{Fortalezas}

- Es el segundo mercado farmacéutico más grande en Centroamérica.

- Mejorar el régimen regulador para aumentar el crecimiento de la demanda farmacéutica a mediano y largo plazo.

- Ambiente favorable para las empresas; atractivo para la inversión multinacional.

- Estrategias proactivas del gobierno para ampliar el acceso a la atención médica y los medicamentos.

\section{Oportunidades}

- Muchos pacientes sin tratamiento previo para ensayos clínicos.

- Mejor acceso a los mercados mediante la armonización normativa regional.

- La modernización del sistema de salud, incluyendo los registros electrónicos de salud aumentará la eficiencia y creará mayores oportunidades de generación de ingresos.

- El Sistema de Seguridad Social de Costa Rica planea destinar más de CRC3. 4 billones (USD6.5 mil millones) de su presupuesto al cuidado de la salud pública y pagos de pensiones durante el año 2017.

- Aumento de la demanda de turismo médico.

\section{Debilidades}

- Bajo gasto farmacéutico per cápita.

- Tamaño moderado de la población.

- El régimen normativo sigue siendo pobre, la falta de transparencia con respecto a las aprobaciones y el registro causa retrasos excesivos para que los medicamentos innovadores lleguen al mercado.

- La ineficiencia de la cadena de suministro conduce a la escasez de medicamentos.

\section{Amenazas}

- Desarrollo económico no cumplido.

- Competencia intensiva en el sector de farmacia.

- Falta de médicos especialistas y profesionales de la salud limita el acceso a la atención médica.

- Posible precio mínimo en la atención médica privada.

Proyecciones de los productos farmacéuticos y atención médica (Costa Rica 2015-2021)

\begin{tabular}{|l|l|l|l|l|l|l|l|}
\hline & 2015 & 2016 & $2017 f$ & $2018 f$ & $2019 f$ & $2020 f$ & $2021 f$ \\
\hline $\begin{array}{l}\text { Ventas farmacéuticas, } \\
\text { USDMM }\end{array}$ & 0.835 & 0.868 & 0.911 & 0.955 & 1,002 & 1,049 & 1,099 \\
\hline $\begin{array}{l}\text { Ventas farmacéuticas, } \\
\% \text { de PIB }\end{array}$ & 1.59 & 1.66 & 1.68 & 1.67 & 1.65 & 1.64 & 1.63 \\
\hline $\begin{array}{l}\text { Ventas farmaceuticas, } \\
\% \text { de gastos en salud }\end{array}$ & 16.9 & 16.9 & 17.0 & 17.0 & 17.1 & 17.2 & 17.3 \\
\hline $\begin{array}{l}\text { Gastos en salud, } \\
\text { USDMM }\end{array}$ & 4,927 & 5,122 & 5,364 & 5,607 & 5,857 & 6,105 & 6,364 \\
\hline
\end{tabular}

$\mathrm{f}=$ Proyección de BMI. Fuente: Base de datos de Comtrade de las Naciones Unidas DESA/UNSD, BMI

Fuentes:

BMiresearch.com 


\section{TENDENCIAS LIFE SCIENCES}

\section{Honduras}

\section{Fortalezas}

- La inversión en la expansión de la cobertura de salud impulsará el crecimiento en la demanda farmacéutica.

- Mejor acceso a los mercados mediante la armonización normativa regional.

\section{Oportunidades}

- El crecimiento económico por encima del promedio mejorará el acceso a medicamentos y servicios de atención médica.

- Un sector de medicamentos genéricos de marca poco penetrado.

\section{Debilidades}

- Se avanzará lentamente en la lucha contra la impunidad a corto plazo. Esto a pesar de los planes para la creación de un organismo anticorrupción en el pais.

- Bajo gasto per cápita: una gran proporción de la población regional es de bajos ingresos, lo cual limita la accesibilidad.

- Uno de los mercados farmacéuticos más pequeños en Centroamérica.

\section{Amenazas}

- La violencia relacionada con el narcotráfico sigue siendo un problema en el país.

- Las instituciones débiles continúan reduciendo la estabilidad política en el país.

- Alta prevalencia de medicamentos falsificados.

Proyecciones de los productos farmacéuticos y atención médica (Honduras 2015-2021)

\begin{tabular}{|l|l|l|l|l|l|l|l|}
\hline & 2015 & 2016 & $2017 f$ & $2018 f$ & $2019 f$ & $2020 f$ & $2021 f$ \\
\hline $\begin{array}{l}\text { Ventas farmacéuticas, } \\
\text { USDMM }\end{array}$ & 0.473 & 0.467 & 0.457 & 0.472 & 0.474 & 0.477 & 0.482 \\
\hline $\begin{array}{l}\text { Ventas farmacéuticas, } \\
\% \text { de PIB }\end{array}$ & 2.26 & 2.18 & 2.09 & 1.99 & 1.91 & 1.82 & 1.74 \\
\hline $\begin{array}{l}\text { Ventas farmaceuticas, } \\
\% \text { de gastos en salud }\end{array}$ & 27.2 & 26.5 & 25.6 & 24.8 & 24.0 & 23.3 & 22.5 \\
\hline $\begin{array}{l}\text { Gastos en salud, } \\
\text { USDMM }\end{array}$ & 1,737 & 1,763 & 1,783 & 1,902 & 1,971 & 2,050 & 2,141 \\
\hline
\end{tabular}

$f=$ Proyección de BMI. Fuente: Fuentes nacionales, BMI

Fuentes:

BMlresearch.com 


\section{TEN DENCIAS LIFE SCIENCES}

\section{Nicaragua}

\section{Fortalezas}

- Mejora en los servicios de salud establecidos para aumentar la demanda de productos

farmacéuticos

- La armonización normativa regional aumentará los volúmenes de ventas y mejorará el acceso a medicamentos.

- Inversión del gobierno para apoyar el desarrollo del sector farmacéutico.

\section{Oportunidades}

- Un sector de medicamentos genéricos poco penetrado.

- Las compañías farmacéuticas se enfrentan a una regulación muy limitada sobre los precios de los medicamentos y el mercadeo.

- Aumento de los programas sociales con el objetivo de mejorar el acceso a los medicamentos.

\section{Debilidades}

- Bajo gasto per cápita: una gran proporción de la población tiene bajos ingresos, lo cual limita la accesibilidad a los medicamentos.

- Uno de los mercados farmacéuticos más pequeños en Centroamérica.

- El entorno empresarial débil atrae una inversión extranjera limitada.

\section{Amenazas}

- Es probable que surjan dificultades económicas a lo largo de los próximos trimestres con una probabilidad de recortes presupuestarios.

- Un entorno operativo cada vez más desafiante continuará pesando sobre la confianza empresarial para las multinacionales en Nicaragua.

- La escasa población de población seguirá desalentando la participación de la industria farmacéutica y la inversion.

Proyecciones de los productos farmacéuticos y atención médica (Nicaragua 2015-2021)

\begin{tabular}{|l|l|l|l|l|l|l|l|}
\hline & 2015 & 2016 & $2017 \mathrm{f}$ & $2018 \mathrm{f}$ & $2019 \mathrm{f}$ & $2020 f$ & $2021 \mathrm{f}$ \\
\hline $\begin{array}{l}\text { Ventas farmacéuticas, } \\
\text { USDMM }\end{array}$ & 0.499 & 0.508 & 0.520 & 0.535 & 0.546 & 0.558 & 0.574 \\
\hline $\begin{array}{l}\text { Ventas farmacéuticas, } \\
\% \text { de PIB }\end{array}$ & 3.93 & 3.78 & 3.70 & 3.64 & 3.56 & 3.48 & 3.42 \\
\hline $\begin{array}{l}\text { Ventas farmacéuticas, } \\
\% \text { de gastos en salud }\end{array}$ & 43.8 & 41.8 & 40.0 & 38.4 & 37.1 & 35.9 & 34.9 \\
\hline $\begin{array}{l}\text { Gastos en salud, } \\
\text { USDMM }\end{array}$ & 1,141 & 1,215 & 1,299 & 1,392 & 1,475 & 1,554 & 1,644 \\
\hline
\end{tabular}

$\mathrm{f}=$ Proyección de BMI. Fuente: Organización Mundial de la Salud (OMS), Base de datos de Comtrade de las Naciones Unidas DESA/UNSD, BMI

\section{Fuentes:}

BMlresearch.com 


\section{TENDENCIAS LIFE SCIENCES}

\section{Fortalezas}

- Trabajar para lograr una asistencia médica universal mejorará e crecimiento de la demanda farmacéutica.

- El gasto farmacéutico per cápita es uno de los más altos de América Latina.

\section{Oportunidades}

- Depende en gran medida de medicamentos importados para

satisfacer la demanda local.

- Panamá ofrece ventajas con respecto a su posición geografica y facilidad de comunicación con centros de investigación en Sudamérica, América del Norte y Europa.

\section{Debilidades}

- Alto consumo de medicamentos genéricos.

- El sistema público de salud fragmentado aumenta los costos de las compras farmacéuticas.

\section{Amenazas}

Desarrollo económico no cumplido.

- Un aumento modesto en la actividad del narcotráfico puede plantear problemas a futuro.

Proyecciones de los productos farmacéuticos y atención médica (Panamá 2015-2021)

\begin{tabular}{|l|l|l|l|l|l|l|l|}
\hline & 2015 & 2016 & $2017 \mathrm{f}$ & $2018 \mathrm{f}$ & $2019 f$ & $2020 \mathrm{f}$ & $2021 \mathrm{f}$ \\
\hline $\begin{array}{l}\text { Ventas farmacéuticas, } \\
\text { USDMM }\end{array}$ & 0.666 & 0.706 & 0.747 & 0.790 & 0.835 & 0.881 & 0.930 \\
\hline $\begin{array}{l}\text { Ventas farmacéuticas, } \\
\% \text { de PIB }\end{array}$ & 1.18 & 1.18 & 1.17 & 1.15 & 1.14 & 1.11 & 1.08 \\
\hline $\begin{array}{l}\text { Ventas farmacéuticas, } \\
\% \text { de gastos en salud }\end{array}$ & 16.4 & 16.0 & 15.5 & 15.0 & 14.6 & 14.2 & 13.8 \\
\hline $\begin{array}{l}\text { Gastos en salud, } \\
\text { USDMM }\end{array}$ & 4,052 & 4,423 & 4,823 & 5,252 & 5,714 & 6,209 & 6,741 \\
\hline
\end{tabular}

$f=$ Proyección de BMI. Fuente: Organización Mundial de la Salud (OMS), Fuentes nacionales, BMI

Fuentes:

BMiresearch.com 


\section{TEN DEN C I AS LIFE SCIENCES}

\section{República Dominicana - Key Facts:}

A continuación se presentan algunos datos relevantes de Life Sciences sector en República Dominicana:

- El valor total de los productos producidos en los laboratorios nacionales pasó de US\$501 millones en el 2015 a US\$435 millones en el 2016.

- Entre el 2010 al 2016 las importaciones de productos farmacéuticos y medicinales pasó de US\$397.2 millones a US\$602.2 millones; es decir, un crecimiento de $51.6 \%$.

- En el mismo periodo las exportaciones de los productos farmacéuticos aumentaron considerablemente. En el 2016 aumentó un 35\%, al pasar de US\$113.2 millones en 2015 a US\$152.7 millones.

De manera general, EY puede ayudar a los clientes a implementar la tecnología digital en toda su cadena de valor:
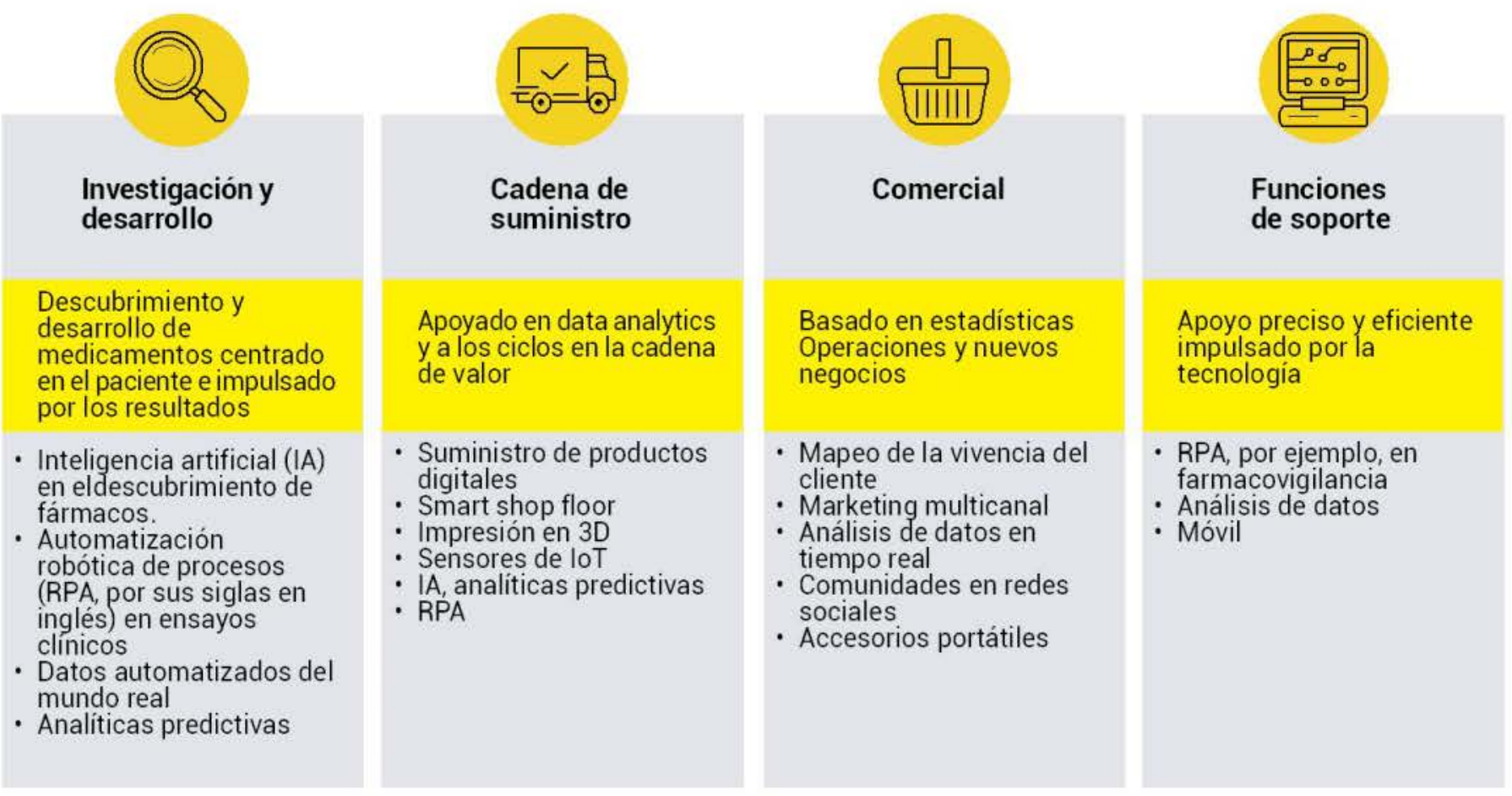

La presente sección enfatizará en la cadena de suministro y en el aspecto comercial.

Fuente:

EY.com. BMlresearch.com. Eldinero.com, listindiario.com, proceso.com.do 


\section{TEN D EN C I AS LIFE SCIENCES}

\section{Cadena de suministros}

Las compañias líderes de life sciences han instalado torres de control integradas; en donde se centraliza la planificación y el control, permitiendo aumentar la visibilidad y sincronizar la cadena de valor de extremo a extremo. Por torre de control se entiende las capacidades estratégicas que permiten a la cadena de suministros disminuir la volatilidad, la complejidad y la incertidumbre a traves de procesos, herramientas y la organización.

El establecimiento de torres de control es un proceso fundamental para la planificación "Lights out", la cual se puede definir como un centro de datos, donde existe automatización de los procesos a través de procesos robóticos y de inteligencia artificial, que se encuentra aislada de la organización, con acceso limitado para reducer costos eléctricos y aumentar la seguridad.

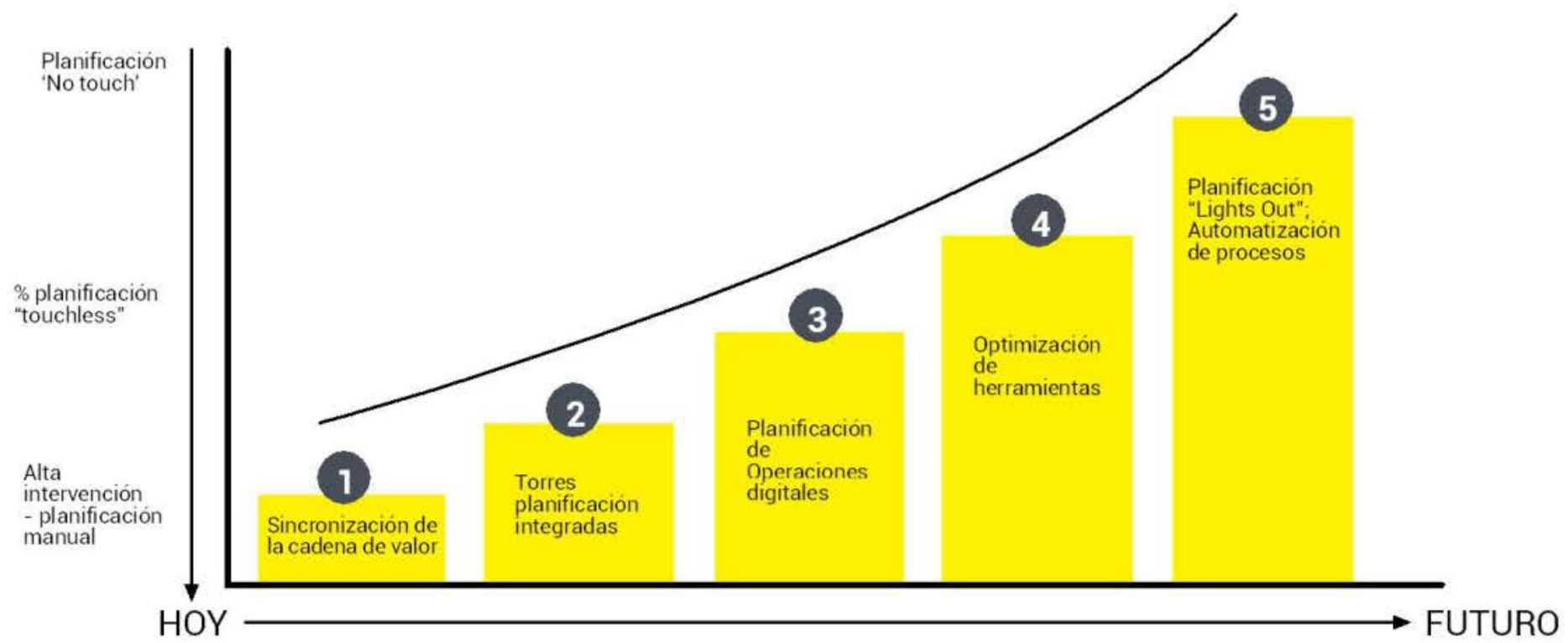

Se debe segmentar y sincronizar la cadena de valor de extremo a extremo con el fin de

1 crear redes de suministros, las cuales son impulsadas por la demanda. De esta manera las personas, los procesos y la tecnología pueden mejorar el rendimiento de los cambios.

Es necesario aumentar el alcance de los servicios realizados en torres de planificación y torres de control. Se deben considerar la utilización de herramientas como integración de

2 planificación avanzada (IBP), la estandarización de los procesos de trabajo, la alineación de ellos a la cadena de valor, robustecer los mismos y estar enfocados en usar herramientas como Lean Manufacturing, Six Sigma, entre otras herramientas y metodologías de calidad.

3 La planificación de operaciones empresariales integradas permite monitorear y controla rápidas a partir de escenarios modelados.

4 Las herramientas utilizadas en la cadena de suministros se deben extender con las últimas aplicaciones.

Realizar cambios positivos en cuánto a la exactitud y efectividad de los costos transaccionales mediante la inteligencia artificial y procesos robóticos.

Fuente:

EY.com. 


\section{TEN DENCI A S LIFE SCIENCES}

\section{Nuestro enfoque integrado para generar valor. mercadeo de omni-canal y de circuito cerrado}

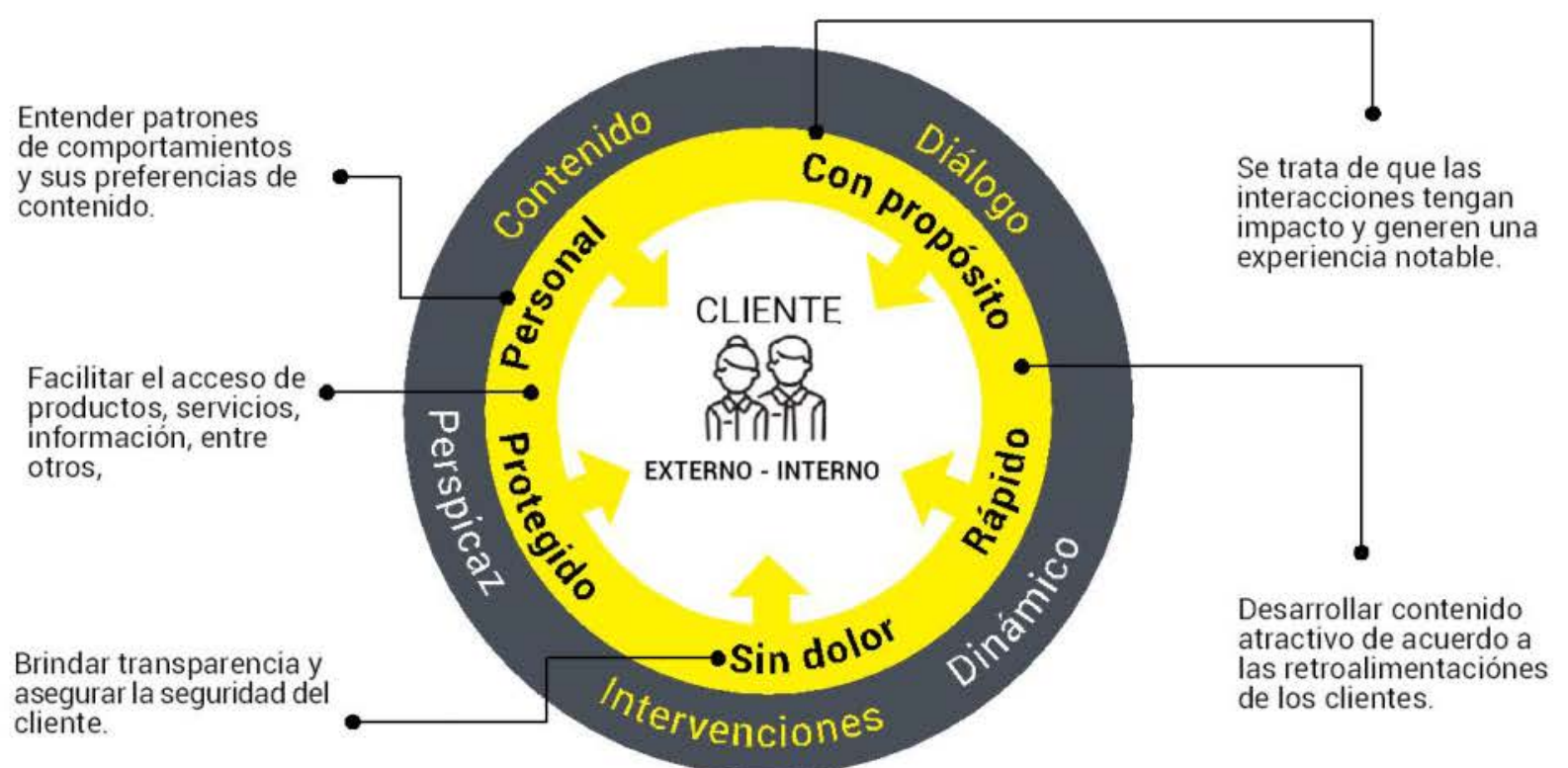

\section{Comercial}

Existen nuevas tecnologías y canales digitales que están provocando cambios en el área comercial. En este aspecto comercial las compañías farmaceúticas han revolucionado la participación y la experiencia de los clientes al considerarlos como socios de confianza. Existen una serie de funciones dentro del mercadeo que están experimentando cambios significativos: los cuales permiten un contacto más rápido con los pacientes.

\section{Áreas / funciones dentro de Mercadeo que están experimentando cambios significativos hoy en día}

\begin{tabular}{|c|c|c|c|c|}
\hline & Educación & $\begin{array}{l}\text { Promoción del } \\
\text { Producto }\end{array}$ & $\begin{array}{l}\text { Intercambio de } \\
\text { conocimientos / } \\
\text { comunidad }\end{array}$ & $\begin{array}{l}\text { Herramientas de } \\
\text { apoyo de decisiones }\end{array}$ \\
\hline \multirow{5}{*}{ 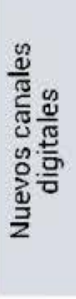 } & \multicolumn{4}{|c|}{ Aplicaciones de teléfonos inteligentes } \\
\hline & \multicolumn{3}{|c|}{ E-detailing } & \multirow{2}{*}{$\begin{array}{l}\text { Herramientas de apoyo de } \\
\text { decisiones clinicas basadas } \\
\text { en la web / aplicaciones }\end{array}$} \\
\hline & \multicolumn{3}{|c|}{ Comunidades en línea, bibliotecas médicas en linea } & \\
\hline & \multicolumn{3}{|c|}{$\begin{array}{l}\text { Red multimedia - Videos en línea, plataformas de aprendizaje electrónico, } \\
\text { ludificación, transmisiones por la web / seminarios por la web }\end{array}$} & \\
\hline & \multicolumn{3}{|c|}{ Medios sociales - Facebook, Twitter } & \\
\hline \multirow{5}{*}{ 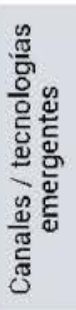 } & Tecnologí & amas en $3 D$ & & Computación cognitiva \\
\hline & Realidad virtual, realidac & R. por sus siglas en inglés) & Conferencias web / virtuales & Inteligencia artificial \\
\hline & \multicolumn{2}{|c|}{ Micrositios } & & Análisis predictivos \\
\hline & \multicolumn{2}{|c|}{ Análisis predictivos, escucha de los medios sociales } & & \\
\hline & \multicolumn{2}{|c|}{ Difusión de videos en vivo } & & \\
\hline
\end{tabular}

Fuente:

EY.com. 


\section{Servicios de EY en Life Sciences}

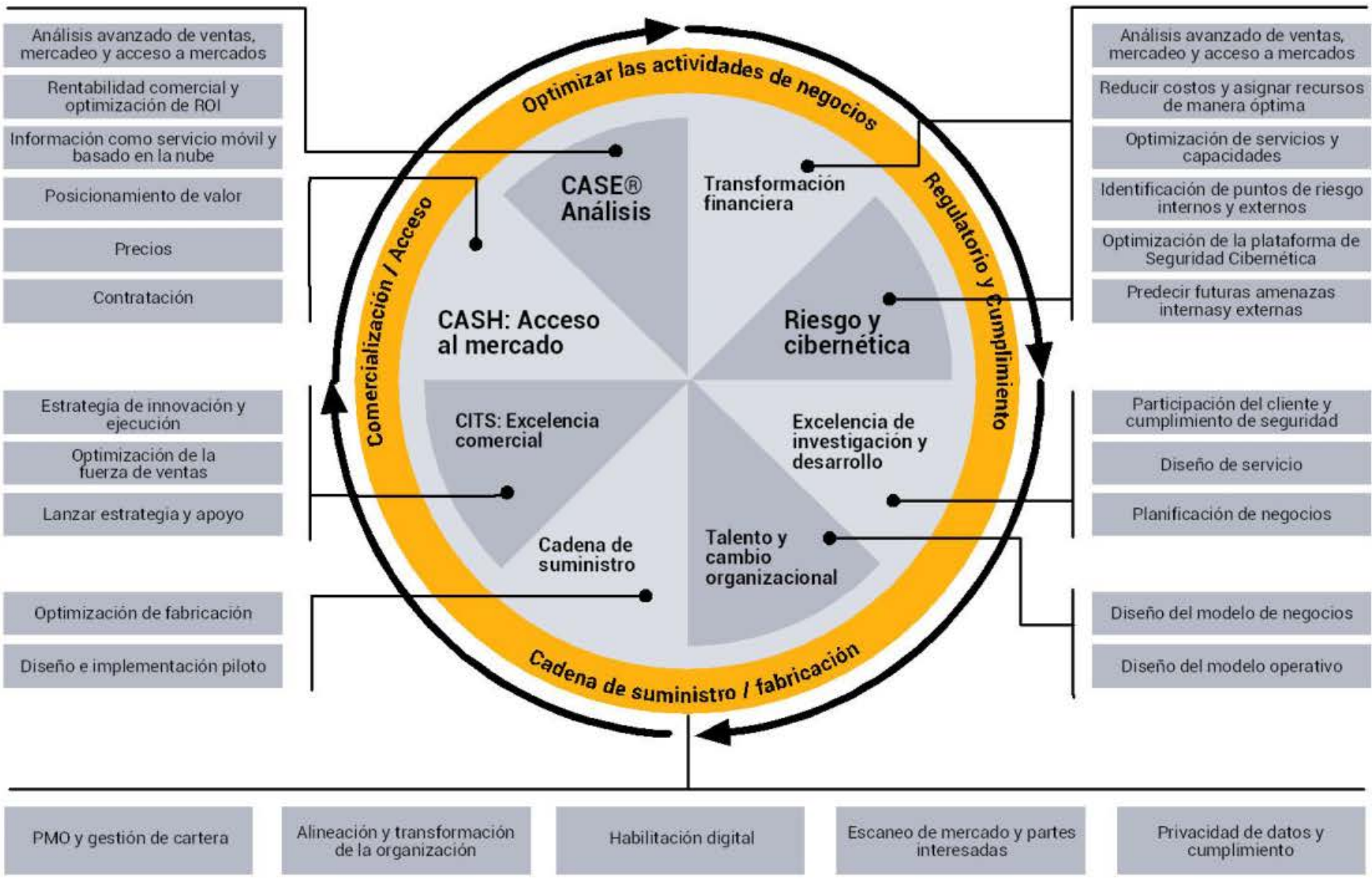

Fuente:

EY.com. 


\section{TEN DENCIAS LIFE SCIENCES}

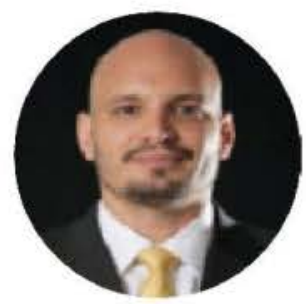

Harold Schoenbeck

Manager I Supply Chain Management \& Operations.

El sector de Life Sciences tiene muchos retos y desafíos actualmente. En los últimos años hemos sido testigos de cómo la inmediatez de la tecnología ha provocado que se rompa la relación entre paciente y doctor. La creación de medicamentos genéricos, también denominados "medicamentos accesibles", ha provocado que la cadena de suministro del sector deba reinventarse para poder hacer frente y mantener la competitividad necesaria, y al alcance del consumidor que interactúa en el omnicanal.

Hay cinco recomendaciones que pueden ayudar y desarrollar resultados para impactar directamente en los costos de la cadena de suministros:

1. La verticalización de la cadena de suministro: la cuál consiste en desarrollar modelos operativos donde los proveedores estén más cerca de los distribuidores y por consiguiente, haya un aumento de comunicación para sincronizar y despachar según la demanda futura.

2. Inventarios negativos: buscar la capacidad a través de alianzas comerciales y lograr que para los proveedores los días de pago sean mayores a los días de cobro de los clientes.

3. Sistemas de "cross docking": eliminar la figura del almacén de las empresas con el fin de que los proveedores despachen directamente a los puntos de venta para disminuir los costos logísticos y del almacenamiento.

4. Algoritmos predictivos y analíticos: identificar la necesidad de cada individuo, personalizarlo y accesarlo a través de la estadística de la probabilidad y el internet de las cosas.

5. Tercerización de la distribución secundaria: en la región los servicios de farmacia a domicilio es un requisito de mercado, pero es necesario una flota de activos para mantener el servicio, lo que provoca que el capital de trabajo se comprometa. Una buena estrategia es ceder este servicio a empresas que se dedican a tercerizar, 3PL (Third Party Logistics).

Entre las tendencias destacan: la presencia de RPA's en biotecnología, asi como en los nuevos equipos de diagnósticos en los hospitales, la transición del almacenamiento magnético hacia la nube (este será uno de los grandes catalizadores que recortarán el ciclo de introducción de nuevas tecnologias y alcanzar más rápido "a seamless supply chain model".

Fuente:

EY.com 


\title{
TENDENCIAS LIFE SCIENCES
}

\author{
EY | Assurance | Tax | Transactions | Consulting
}

Acerca de EY

EY es un líder global en servicios de auditoria, impuestos, transacciones y consultoría. Nuestro conocimiento, puntos de vista y servicios de calidad ayudan a generar confianza en los mercados de capital y en las economías alrededor del mundo. Desarrollamos líderes excepcionales que trabajan en equipo para cumplir las promesas hechas a todos nuestros grupos de interés. Al hacerlo, desempeñamos un papel fundamental en la construcción de un mejor mundo de negocios para nuestra gente, nuestros clientes y nuestras comunidades.

EY se refiere a la organización global de firmas miembro conocidas como Ernst \& Young Global Limited, en la que cada una de ellas actúa como una entidad legal separada. Ernst \& Young Global Limited, compañía del Reino Unido limitada por garantía, no provee servicios a clientes. Más información en www.ey.com.

(c) 2018 E\&Y Central America Inc.

Todos los derechos reservados.

Esta publicación contiene información en forma de resumen y, por lo tanto, su uso es solo para orientación general. No debe considerarse como sustituto de la investigación detallada o del ejercicio de un criterio profesional. Ni E\&Y Central America Inc., ni ningún otro miembro de la organización global de EY acepta responsabilidad alguna por la pérdida ocasionada a cualquier persona que actúe o deje de actuar como resultado de algún contenido en esta publicación. Sobre cualquier asunto en particular, referirse al asesor apropiado.

Los puntos de vista de terceros expuestos en la presente publicación no necesariamente son los puntos de vista de la organización global de $E Y$ o de sus firmas integrantes. Por ende, dichos puntos de vista se deben tomar en el contexto del momento en que se expresaron.

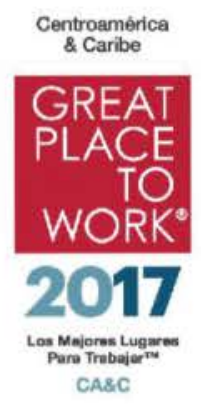

